\title{
Membrane transporter proteins are involved in Trichophyton rubrum pathogenesis
}

Correspondence

Nilce M. Martinez-Rossi

nmmrossi@usp.br

Received 27 April 2008

Accepted 7 October 2008

\author{
Fernanda C. A. Maranhão, Fernanda G. Paião, Ana Lúcia Fachint \\ and Nilce M. Martinez-Rossi
}

Departamento de Genética, Faculdade de Medicina de Ribeirão Preto, Universidade de São Paulo, 14049-900 Ribeirão Preto, São Paulo, Brazil

\begin{abstract}
Trichophyton rubrum is a dermatophyte responsible for the majority of human superficial mycoses. The functional expression of proteins important for the initial step and the maintenance of the infection process were identified previously in T. rubrum by subtraction suppression hybridization after growth in the presence of keratin. In this study, sequences similar to genes encoding the multidrug-resistance ATP-binding cassette (ABC) transporter, copper ATPase, the major facilitator superfamily and a permease were isolated, and used in Northern blots to monitor the expression of the genes, which were upregulated in the presence of keratin. A sequence identical to the TruMDR2 gene, encoding an ABC transporter in T. rubrum, was isolated in these experiments, and examination of a T. rubrum $\triangle$ TruMDR2 mutant showed a reduction in infecting activity, characterized by low growth on human nails compared with the wild-type strain. The high expression levels of transporter genes by T. rubrum in mimetic infection and the reduction in virulence of the $\triangle T$ TruMDR2 mutant in a disease model in vitro suggest that transporters are involved in T. rubrum pathogenicity.
\end{abstract}

\section{INTRODUCTION}

Fungal infections can cause morbidity in immunosuppressed individuals, particularly those undergoing transplants and chemotherapy, and human immunodeficiency virus-positive patients, showing the importance of early diagnosis and appropriate antifungal therapy (Erbagci, 2002; Nir-Paz et al., 2003). The dermatophytes - fungi specialized in keratin degradation - are frequently involved in chronic infections that affect humans on a global scale. The most prevalent dermatophyte is Trichophyton rubrum, which has been isolated from tinea corporis, tinea unguium and tinea pedis infections (Summerbell, 1997; Weitzman \& Summerbell, 1995).

Several studies have provided evidence that a $\mathrm{pH}$ environment-mediated effect regulates fungal gene expression and secretory activity (Casadevall \& Pirofski, 2001; Ferreira-Nozawa et al., 2006), both of which play a role in pathogenicity. During keratin degradation, dermatophytes have been shown to secrete specific enzymes, depending on

†Present address: Departamento de Biotecnologia, Universidade de Ribeirão Preto, Ribeirão Preto, São Paulo, Brazil.

Abbreviations: ABC, ATP-binding cassette; EST, expressed sequence tag; MDR, multidrug resistance; MFS, major facilitator superfamily; $\mathrm{SSH}$, suppression subtractive hybridization.

The GenBank/EMBL/DDBJ accession numbers for the EST sequences of $T$. rubrum reported in this study are EB086877-EB086879, EB086887 and EH038250. sensing of the host ambient pH (Maranhão et al., 2007; Martinez-Rossi et al., 2004). A regulatory sensing system in the response of $T$. rubrum towards carbon-source availability and the ability to adapt in the host is essential for the survival of this fungus (Ferreira-Nozawa et al., 2006; Kunert, 1972, 1976), inducing the expression of enzymes and membrane transporters that facilitate the uptake of amino acids (Grobler et al., 1995; Lechenne et al., 2007). Furthermore, specific genes need to be expressed to enable these mechanisms, which are involved in the activation of signal transduction for maintenance of the infection process under keratin contact. The occurrence of therapeutic failures due to the development of resistance is often associated with efflux pumps in the cell membrane (Martinez-Rossi et al., 2008; Prasad et al., 2006). Recent observations have indicated that membrane transporters are commonly involved in bacterial and fungal pathogenesis, with important roles as virulence factors to ensure successful colonization in a host environment (Mishra et al., 2007). The TruMDR1 gene of T. rubrum encodes an ATP-binding cassette $(\mathrm{ABC})$ transporter and is expressed differentially in the presence of antifungals such as griseofulvin and itraconazole (Cervelatti et al., 2006). Early genetic knockout analysis of a $\triangle T r u M D R 2$ strain has shown that a TruMDR2 transporter-mediated toxicant efflux mechanism plays a role in modulating susceptibility to terbinafine, 4-nitroquinoline $N$-oxide and ethidium bromide in T. rubrum (Fachin et al., 2006). The aim of this study was to investigate the differential expression of genes 
encoding proteins similar to transporters in the dermatophyte T. rubrum grown in medium containing keratin, and to compare growth characteristics between a wild-type and a $\triangle T r u M D R 2$ strain during nail infection. Our findings suggest that membrane transporter proteins are important in the dermatophyte infection process, adding new knowledge about the gene expression profile of T. rubrum.

\section{METHODS}

Fungal strains and culture conditions for expression analyses. The T. rubrum H6 (wild-type) strain (ATCC MYA-3108) and strain $\triangle T r u M D R 2$ (Fachin et al., 2006) were used throughout this study and were cultured as described previously (Fachin et al., 1996). In expression assays, T. rubrum wild-type conidia were grown in liquid minimal medium with nitrate $(70 \mathrm{mM})$ as the nitrogen source (Cove, 1966), supplemented with keratin in the test sample $\left(2.5 \mathrm{~g} \mathrm{ml}^{-1}\right)$ to promote specific gene expression, or with glucose in the control sample $(55 \mathrm{mM})$, for $72 \mathrm{~h}$ at $28{ }^{\circ} \mathrm{C}$ at an initial $\mathrm{pH}$ of 5.0.

Isolation of RNA, cDNA synthesis and construction of suppression subtractive hybridization (SSH) library. Total RNA from the wild-type T. rubrum strain was extracted from approximately $100 \mathrm{mg}$ frozen mycelium using TRIzol reagent (Invitrogen). The quality and concentration of total RNA were checked by formaldehyde/agarose gel electrophoresis and a spectrophotometer. A $1 \mu \mathrm{g}$ sample was used for double-stranded cDNA synthesis using a BD SMART PCR cDNA synthesis kit (BD Biosciences Clontech), according to the manufacturer's guidelines. An SSH library was constructed as described by Diatchenko et al. (1996) and Maranhão et al. (2007) using a PCR Select cDNA subtraction kit (BD Biosciences Clontech). We used T. rubrum mycelia treated in the presence of keratin as the tester population and in the presence of glucose as the driver population. The final PCR sample obtained corresponded to genes differently expressed when this dermatophyte was in contact with keratin. All PCR products were cloned into the pGEM-T Easy vector system (Promega) and transformed into Escherichia coli (Mos Blue). After selection by X-Gal/IPTG, white colonies were picked and grown in Luria-Bertani medium with selection by ampicillin and tetracycline resistance for $20 \mathrm{~h}$ at $37^{\circ} \mathrm{C}$, and stored until needed for the next steps.

DNA sequencing and Northern blotting. The cDNA clones were sequenced on an ABI Prism 377 DNA sequencer (Applied Biosystems), using M13 forward and reverse primers. The sequences were processed using the PhredPhrap-Consed package and submitted for similarity searches against the non-redundant GenBank database using BLASTX software at the National Center for Biotechnology Information (http://www.ncbi.nlm.nih.gov) (Altschul et al., 1997). Clones with inserts corresponding to transporter genes were selected for use as probes in Northern blotting analysis.

For validation of differential gene expression by Northern blotting, $T$. rubrum was cultivated under test and control conditions (keratin and glucose, respectively). Total RNA $(15 \mu \mathrm{g})$ from $T$. rubrum grown under each condition was separated by electrophoresis on a $1.5 \%$ agarose/formaldehyde gel and subsequently transferred to nylon membranes (Hybond- ${ }^{+}$; Amersham) using a vacuum blotter (BioDot; Bio-Rad). Probes were purified from plasmids containing inserts of the specific transporter genes by PCR amplification. All probes (50 ng) were labelled by random priming (Random Primers DNA labelling system; Gibco-BRL) and $\left[\alpha^{32} \mathrm{P}\right] \mathrm{dCTP}$. Hybridization was performed overnight at $65{ }^{\circ} \mathrm{C}$ with agitation, and membranes were washed using standard protocols (Sambrook et al., 1989) and exposed to storage phosphor screens (Applied Biosystems). The intensity level of each transcript was quantified based on the number of digital light units generated using OptiQuant (Perkin Elmer) after subtracting the background. The Northern blotting results shown are representative of two independent experiments.

Infection assays. Infection in vitro was performed as described by Takasuka (2000). Human nail fragments of approximately $1 \times 1 \mathrm{~mm}$ were treated with ethanol for $15 \mathrm{~min}$ and dried at room temperature. A $5 \mu \mathrm{l}$ aliquot of a conidial suspension $\left(3 \times 10^{6} \mathrm{ml}^{-1}\right)$ of each $T$. rubrum strain (wild-type and mutant) was soaked onto individual nail fragments for $1 \mathrm{~h}$, followed by the addition of $200 \mu \mathrm{l}$ distilled water in Eppendorf tubes. The tubes were incubated at $28{ }^{\circ} \mathrm{C}$ for 6 days, and fungal growth was observed by light microscopy (Axion Vision system; Zeiss). Nail fragments soaked in $200 \mu$ l distilled water were used as a control.

\section{RESULTS AND DISCUSSION}

\section{Identification of transporter genes by SSH and bioinformatic analyses}

In this study, we investigated the expression of several genes that may affect T. rubrum pathogenesis. After the isolation of genes differentially expressed by SSH, which used T. rubrum mycelium cultivated in keratin as the test condition, a BLASTX analysis was performed and 66 clones similar to genes encoding putative transporters from different families were identified. These represented $27.7 \%$ of the cDNA clones isolated after T. rubrum was grown in the presence of keratin (Maranhão et al., 2007). From the 66 subtractive cDNA clones screened, 5 non-redundant unique expressed sequence tags (ESTs) were generated. These ESTs, named TR0042, TR0043, TR0044, TR0052 and TR0097 (GenBank accession nos EB086877, EB086878, EB086879, EB086887 and EH038250), were predicted to encode proteins corresponding to the major facilitator superfamily (MFS) peptide transporter, copper resistance-associated P-type ATPase, multidrug-resistance (MDR) transporter, amino acid permease and V-type ATPase, respectively (Table 1). Most of these proteins show similarity to well-known homologues in Aspergillus fumigatus. MFS proteins, members of a large transporter family, occurred at a high incidence (57.6\%) among the transporter proteins expressed in T. rubrum grown in the presence of keratin (Table 1).

It is known that the human skin has a $\mathrm{pH}$ of approximately 5.0 (Marro et al., 2001) and contains keratinized elements, which are important factors for dermatophyte infection. Thus, our experiments were performed at an initial $\mathrm{pH}$ of 5.0 , with keratin or glucose as the carbon source. The results were obtained after $72 \mathrm{~h}$ of T. rubrum cultivation (when the keratin medium reached $\mathrm{pH}$ 8.4), an experimental condition appropriate for the isolation of genes likely to be involved in the maintenance of infection, which are preferentially expressed at alkaline pH (Maranhão et al., 2007).

\section{Expression of transporter genes in T. rubrum}

Northern blot analysis was carried out with total RNA isolated from the mycelia of wild-type T. rubrum $\mathrm{H} 6$ strain 
Table 1. T. rubrum transporter genes overexpressed during growth in the presence of keratin

\begin{tabular}{|c|c|c|c|c|c|c|}
\hline TR0042 & EB086877 & 634 & $\begin{array}{l}\text { A. fumigatus, MFS peptide transporter, } \\
\text { putative, XP_746951 }\end{array}$ & $1 e-69$ & 66 & 38 \\
\hline TR0097 & EH038250 & 224 & $\begin{array}{l}\text { A. fumigatus, V-type ATPase, subunit B, } \\
\text { XP_755656 }\end{array}$ & $6 e-20$ & 92 & 16 \\
\hline TR0043 & EB086878 & 176 & $\begin{array}{l}\text { A. fumigatus, copper resistance-asso- } \\
\text { ciated P-type ATPase, XP_754347 }\end{array}$ & $2 e-15$ & 75 & 2 \\
\hline TR0052 & EB086887 & 723 & $\begin{array}{l}\text { A. fumigatus, amino acid permease, } \\
\text { putative acid permease, AAC } 98709\end{array}$ & $8 e-12$ & 57 & 1 \\
\hline
\end{tabular}

cultivated with keratin or glucose. The mRNA steady-state levels of genes encoding specific efflux pumps, a metal transporter, the MFS and a permease were detected by Northern blotting analysis under test conditions, during germination in keratin-containing medium, revealing that the expression of specific transporters in this test medium was higher than that in glucose-containing medium (Fig. 1). The ABC and MFS transporters are two major classes of proteins involved in drug resistance. The substrate range of both membrane transporters is very broad and may include ions, amino acids, peptides, sugars, secondary metabolites and drugs. Several studies have investigated the role of the MDR transporter in response to metabolic poisons and antifungal drugs (Prasad et al., 2006). BLASTX analysis revealed the identity of a sequence that was highly upregulated in the test cDNA population
(TR0044, GenBank accession no. EB086879) with a $T$. rubrum MDR-like ABC transporter, a multidrug pump efflux (Fachin et al., 2006). Fungal ABC transporters play a function as efflux pumps, providing resistance to several antifungal types (Mishra et al., 2007; Urban et al., 1999). In addition, ABC-encoding genes have been identified as an important pathogenicity determinant in the early stages of filamentous fungi pathogenesis, as demonstrated for the ABC1 from Magnaporthe grisea, BcatrB from Botrytis cinerea and GpABC1 from Gibberella pulicaris. (Fleissner et al., 2002; Gupta \& Chattoo, 2008; Vermeulen et al., 2001).

Additionally, the Northern blotting analyses with a probe similar to the MFS transporter-encoding gene showed a strong signal under the test keratin conditions (Fig. 1).
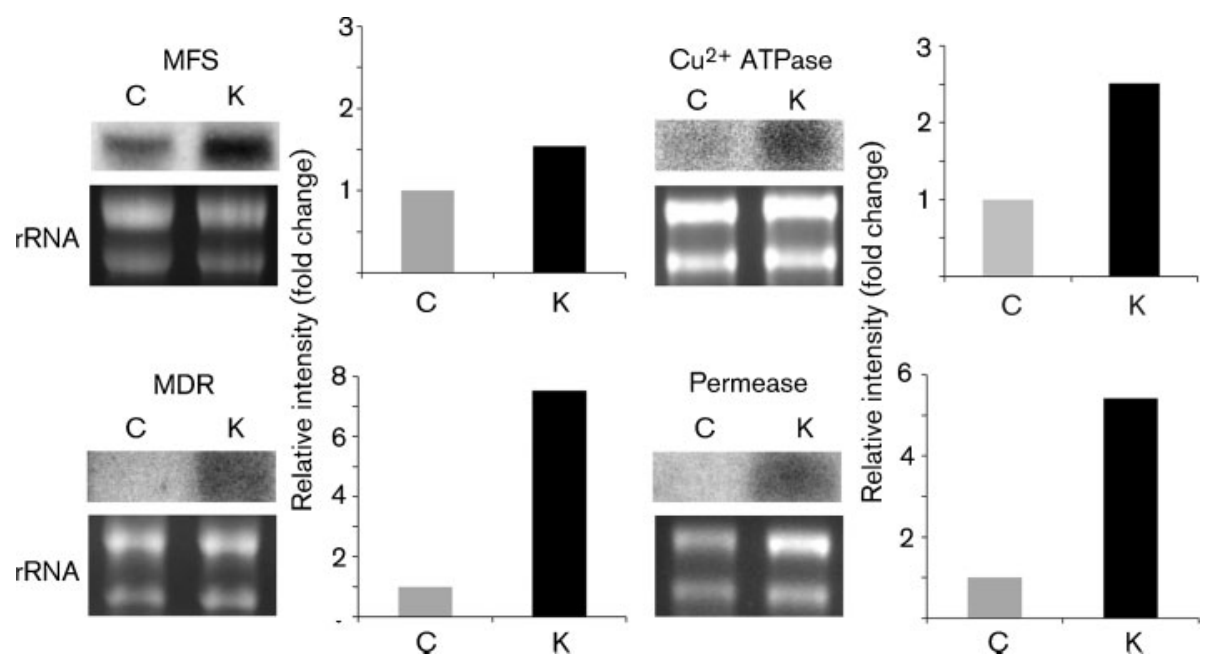

Fig. 1. Northern blotting analyses showing differential expression of T. rubrum genes encoding an MFS transporter (TR0042), a copper $\left(\mathrm{Cu}^{2+}\right.$ ) ATPase (TR0043), an ABC MDR transporter (TR0044) and a permease (TR0052), using total RNA from wildtype strain $\mathrm{H} 6$. This strain was cultivated in glucose as a control (C) and in keratin (K). Ethidium bromide-stained rRNA shows the relative loading of the samples. The graphs indicate the fold differences in the intensity of the Northern blots shown by each clone expressed in the $\mathrm{H} 6$ strain cultivated under control and test conditions, as established by densitometry analysis using a Phosphorlmager. 
Although a large number of clones similar to MFSencoding gene were isolated by SSH when T. rubrum was grown in keratin-containing medium, we also detected a weak hybridization signal under control conditions in comparison with the test sample. This result was expected because MFS transporters are a ubiquitous group of proteins involved in the transport of a wide range of compounds, including external elements and toxins (Saier et al., 1999; Vardy et al., 2004). In the Aspergillus oryzae genome, $63.9 \%$ of transporters are MFS type, involved in secondary metabolism (Akao et al., 2007). The analysis of a gene encoding MFS transporter-like protein (CTB4) in Cercospora nicotianae provided genetic evidence to support its role in virulence by cercosporin accumulation (Choquer et al., 2007). In this study, experiments with a Cercospora nicotianae mutant displayed a drastic reduction in cercosporin production and accumulation, causing fewer lesions on tobacco leaves (Choquer et al., 2007).

Expression of the copper ATPase-encoding sequence was just detectable as an approximately $3 \mathrm{~kb}$ transcript in the wild-type strain grown in minimal medium containing keratin. A subtractive library enriched by T. rubrum genes expressed in the presence of cytotoxic components showed the upregulation of a gene encoding copper-resistanceassociated P-type ATPase after fluconazole contact (Paião et al., 2007). Copper is an essential metabolic element as a cofactor of many cellular enzymes, and copper-transporting P-type ATPases are found in eukaryotic organisms and require an iron transporter for adaptation in different environments and hosts (Riggle \& Kumamoto, 2000). The absence of normal copper-transporter activity in Cryptococcus neoformans after VPH1 gene deletion was observed in an avirulent mutant interfering in laccase activity (Zhu \& Williamson, 2003), a strong virulence factor in this opportunistic pathogen. In addition, a disruption in the Candida albicans CaCCC2 gene led to an unusual phenotype of silver and copper resistance (Weissman et al., 2002), and a clap1 mutation in Colletotrichum lindemuthianum caused a non-pathogenic phenotype (Parisot et al., 2002), both genes encoding a putative copper-transporting ATPase.
The virulence capacity was also affected in Listeria monocytogenes mutants, carrying a mutation in cptA, a gene involved in copper homeostasis (Francis \& Thomas, 1997). Furthermore, our Northern blot experiments also demonstrated that a permease, a general transporter, was highly expressed in T. rubrum cultures growing in the test medium.

\section{Assay of infection by $\triangle T$ TruMDR2}

The effect of disrupting the TruMDR2 gene (TR0044 cDNA) on the pathogenicity of T. rubrum was assessed in the nail model in vitro, to test the infection ability of the $\triangle T r u M D R 2$ strain mutant in comparison with wild-type H6. Conidia preparations of wild-type and mutant strains were distributed separately on sterile nails, and growth was observed by microscopy 6 days after inoculation and incubation at $28{ }^{\circ} \mathrm{C}$. The deletion of TruMDR2 was found to correlate with a decreased ability of the $\triangle T r u M D R 2$ mutant to grow on human nail (Fig. 2), a major infection site of T. rubrum.

The TruMDR2 gene, encoding an ABC MDR transporter in T. rubrum, is also highly expressed after exposure to acriflavine, ketoconazole, chloramphenicol, griseofulvin, fluconazole and other cytotoxic agents, as revealed by Northern blotting of the wild-type strain. Also, the mutant $\triangle T r u M D R 2$ is more sensitive to terbinafine, 4-nitroquinoline $\mathrm{N}$-oxide and ethidium bromide than the control strain, confirming the involvement of this gene in drug transport (Fachin et al., 2006). The MDR genes may affect other aspects of metabolism and nutrient availability, and, in our T. rubrum infection assays in nails, the mutant phenotype of the $\triangle T r u M D R 2$ strain was found to correlate strictly with decreased growth on human nails.

In conclusion, the capacity of infecting fungi to regulate their gene expression and overcome host resistance is crucial in the virulence of dermatophytes. The expression of several transporters reported in our studies confirmed that a membrane transporter system is required for optimal growth on keratin sources and may reflect a regulatory role in the establishment of dermatophytoses at the host site. (a)

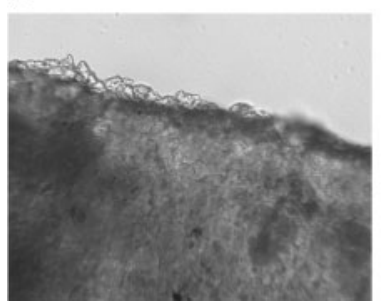

(b)

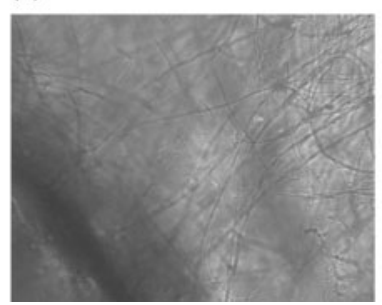

(c)

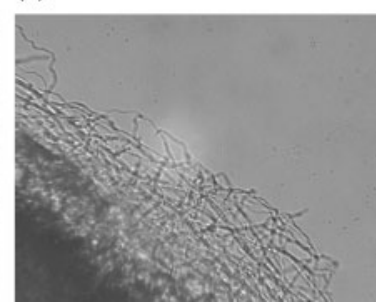

Fig. 2. Infection assays showing the growth of different T. rubrum strains cultivated on human nail for 6 days at $28{ }^{\circ} \mathrm{C}$. The fungal growth on human nails was observed by light microscopy and the images were captured using an Axio Vision system (Zeiss) with a Plan Neofluar $20 \times 0.5$ objective. The black regions on the left side of the images are nail fragments: (a) negative control (no inoculum); (b) H6 (wild-type) strain; (c) $\Delta$ TruMDR2 strain. Representative results of two experiments are shown. 
Furthermore, by using nail fragments as the only source of nutrients, we found that the $\triangle T r u M D R 2$ mutant grew poorly compared with the control wild-type strain, suggesting that the TruMDR2 gene may be involved in the virulence of T. rubrum.

\section{ACKNOWLEDGEMENTS}

This work was supported by grants from the Brazilian agencies FAPESP, CNPq, CAPES and FAEPA. We thank R. A. P. Ferreira, A. C. C. Souza and M. Mazucato for technical support, P. R. Sanches for bioinformatic assistance and A. Borghi for a review of the English.

\section{REFERENCES}

Akao, T., Sano, M., Yamada, O., Akeno, T., Fujii, K., Goto, K., OhashiKunihiro, S., Takase, K., Yasukawa-Watanabe, M. \& other authors (2007). Analysis of expressed sequence tags from the fungus Aspergillus oryzae cultured under different conditions. DNA Res 14, 47-57.

Altschul, S. F., Madden, T. L., Schaffer, A. A., Zhang, J., Zhang, Z., Miller, W. \& Lipman, D. J. (1997). Gapped BLAST and PSI-BLAST: a new generation of protein database search programs. Nucleic Acids Res $\mathbf{2 5}$ 3389-3402.

Casadevall, A. \& Pirofski, L. (2001). Host-pathogen interactions: the attributes of virulence. J Infect Dis 184, 337-344.

Cervelatti, E. P., Fachin, A. L., Ferreira-Nozawa, M. S. \& MartinezRossi, N. M. (2006). Molecular cloning and characterization of a novel $\mathrm{ABC}$ transporter gene in the human pathogen Trichophyton rubrum. Med Mycol 44, 141-147.

Choquer, M., Lee, M. H., Bau, H. J. \& Chung, K. R. (2007). Deletion of a MFS transporter-like gene in Cercospora nicotianae reduces cercosporin toxin accumulation and fungal virulence. FEBS Lett 581, 489-494.

Cove, D. J. (1966). The induction and repression of nitrate reductase in the fungus Aspergillus nidulans. Biochim Biophys Acta 113, 51-56.

Diatchenko, L., Lau, Y. F., Campbell, A. P., Chenchik, A., Moqadam, F., Huang, B., Lukyanov, S., Lukyanov, K., Gurskaya, N. \& other authors (1996). Suppression subtractive hybridization: a method for generating differentially regulated or tissue-specific cDNA probes and libraries. Proc Natl Acad Sci U S A 93, 6025-6030.

Erbagci, Z. (2002). Deep dermatophytoses in association with atopy and diabetes mellitus: Majocchi's granuloma tricophyticum or dermatophytic pseudomycetoma? Mycopathologia 154, 163-169.

Fachin, A. L., Maffei, C. M. \& Martinez-Rossi, N. M. (1996). In vitro susceptibility of Trichophyton rubrum isolates to griseofulvin and tioconazole. Induction and isolation of a resistant mutant to both antimycotic drugs. Mycopathologia 135, 141-143.

Fachin, A. L., Ferreira-Nozawa, M. S., Maccheroni, W., Jr \& MartinezRossi, N. M. (2006). Role of the ABC transporter TruMDR2 in terbinafine, 4-nitroquinoline $\mathrm{N}$-oxide and ethidium bromide susceptibility in Trichophyton rubrum. J Med Microbiol 55, 1093-1099.

Ferreira-Nozawa, M. S., Silveira, H. C., Ono, C. J., Fachin, A. L., Rossi, A. \& Martinez-Rossi, N. M. (2006). The $\mathrm{pH}$ signaling transcription factor PacC mediates the growth of Trichophyton rubrum on human nail in vitro. Med Mycol 44, 641-645.

Fleissner, A., Sopalla, C. \& Weltring, K. M. (2002). An ATP-binding cassette multidrug-resistance transporter is necessary for tolerance of Gibberella pulicaris to phytoalexins and virulence on potato tubers. Mol Plant Microbe Interact 15, 102-108.
Francis, M. S. \& Thomas, C. J. (1997). Mutants in the CtpA copper transporting P-type ATPase reduce virulence of Listeria monocytogenes. Microb Pathog 22, 67-78.

Grobler, J., Bauer, F., Subden, R. E. \& Van Vuuren, H. J. (1995). The mael gene of Schizosaccharomyces pombe encodes a permease for malate and other C4 dicarboxylic acids. Yeast 11, 1485-1491.

Gupta, A. \& Chattoo, B. B. (2008). Functional analysis of a novel ABC transporter ABC4 from Magnaporthe grisea. FEMS Microbiol Lett 278, 22-28.

Kunert, J. (1972). Keratin decomposition by dermatophytes: evidence of the sulphitolysis of the protein. Experientia 28, 1025-1026.

Kunert, J. (1976). Keratin decomposition by dermatophytes. II. Presence of $S$-sulfocysteine and cysteic acid in soluble decomposition products. Z Allg Mikrobiol 16, 97-105.

Lechenne, B., Reichard, U., Zaugg, C., Fratti, M., Kunert, J., Boulat, O. \& Monod, M. (2007). Sulphite efflux pumps in Aspergillus fumigatus and dermatophytes. Microbiology 153, 905-913.

Maranhão, F. C., Paião, F. G. \& Martinez-Rossi, N. M. (2007). Isolation of transcripts over-expressed in human pathogen Trichophyton rubrum during growth in keratin. Microb Pathog 43, $166-172$.

Marro, D., Guy, R. H. \& Delgado-Charro, M. B. (2001). Characterization of the iontophoretic permselectivity properties of human and pig skin. J Control Release 70, 213-217.

Martinez-Rossi, N. M., Ferreira-Nozawa, M. S., Graminha, M. A. S., Nozawa, S. R., Fachin, A. L., Cervelatti, E. P., Prade, R. A. \& Rossi, A. (2004). Molecular aspects of dermatophyte-host interactions. In Fungi in Human and Animal Health, pp. 143-165. Edited by R. K. S. Kushwaha. India: Scientific Publishers.

Martinez-Rossi, N. M., Peres, N. T. A. \& Rossi, A. (2008). Antifungal resistance mechanisms in dermatophytes. Mycopathologia 166, 369383.

Mishra, N. N., Prasad, T., Sharma, N., Payasi, A., Prasad, R., Gupta, D. K. \& Singh, R. (2007). Pathogenicity and drug resistance in Candida albicans and other yeast species. A review. Acta Microbiol Immunol Hung 54, 201-235.

Nir-Paz, R., Elinav, H., Pierard, G. E., Walker, D., Maly, A., Shapiro, M., Barton, R. C. \& Polacheck, I. (2003). Deep infection by Trichophyton rubrum in an immunocompromised patient. J Clin Microbiol 41, 5298-5301.

Paião, F. G., Segato, F., Cursino-Santos, J. R., Peres, N. T. \& Martinez-Rossi, N. M. (2007). Analysis of Trichophyton rubrum gene expression in response to cytotoxic drugs. FEMS Microbiol Lett 271, $180-186$.

Parisot, D., Dufresne, M., Veneault, C., Lauge, R. \& Langin, T. (2002). clap1, a gene encoding a copper-transporting ATPase involved in the process of infection by the phytopathogenic fungus Colletotrichum lindemuthianum. Mol Genet Genomics 268, 139-151.

Prasad, R., Gaur, N. A., Gaur, M. \& Komath, S. S. (2006). Efflux pumps in drug resistance of Candida. Infect Disord Drug Targets 6, 69-83.

Riggle, P. J. \& Kumamoto, C. A. (2000). Role of a Candida albicans P1-type ATPase in resistance to copper and silver ion toxicity. $J$ Bacteriol 182, 4899-4905.

Saier, M. H., Jr, Beatty, J. T., Goffeau, A., Harley, K. T., Heijne, W. H., Huang, S. C., Jack, D. L., Jahn, P. S., Lew, K. \& other authors (1999). The major facilitator superfamily. J Mol Microbiol Biotechnol 1, 257279.

Sambrook, J., Fritsch, E. F. \& Maniatis, T. (1989). Molecular Cloning: a Laboratory Manual, 2nd edn. Cold Spring Harbor, NY: Cold Spring Harbor Laboratory. 
Summerbell, R. C. (1997). Epidemiology and ecology of onychomycosis. Dermatology 194 (Suppl. 1), 32-36.

Takasuka, T. (2000). Amino acid- or protein-dependent growth of Trichophyton mentagrophytes and Trichophyton rubrum. FEMS Immunol Med Microbiol 29, 241-245.

Urban, M., Bhargava, T. \& Hamer, J. E. (1999). An ATP-driven efflux pump is a novel pathogenicity factor in rice BLAST disease. EMBO J 18, 512-521.

Vardy, E., Arkin, I. T., Gottschalk, K. E., Kaback, H. R. \& Schuldiner, S. (2004). Structural conservation in the major facilitator superfamily as revealed by comparative modeling. Protein Sci 13, 1832-1840.
Vermeulen, T., Schoonbeek, H. \& De Waard, M. A. (2001). The ABC transporter BcatrB from Botrytis cinerea is a determinant of the activity of the phenylpyrrole fungicide fludioxonil. Pest Manag Sci 57, 393-402.

Weissman, Z., Shemer, R. \& Kornitzer, D. (2002). Deletion of the copper transporter CaCCC2 reveals two distinct pathways for iron acquisition in Candida albicans. Mol Microbiol 44, 1551-1560.

Weitzman, I. \& Summerbell, R. C. (1995). The dermatophytes. Clin Microbiol Rev 8, 240-259.

Zhu, X. \& Williamson, P. R. (2003). A CLC-type chloride channel gene is required for laccase activity and virulence in Cryptococcus neoformans. Mol Microbiol 50, 1271-1281. 